\title{
The Introduction of the Reserve Clause in Major League Baseball: Evidence of its Impact on Select Player Salaries During the 1880s
}

\author{
Jennifer K. Ashcraft ${ }^{\dagger}$ and Craig A. Depken, $\mathrm{II}^{\dagger \dagger}$
}

April 2007

\begin{abstract}
This paper investigates the introduction of the reserve clause in Major League Baseball during the 1880s. Taking advantage of a unique data set describing the salaries for twenty nine high-quality players throughout the decade of the 1880s, we investigate the impact of the reserve clause as it evolved from a "gentleman's agreement" to a formal contract stipulation. We test three specific hypotheses concerning the reserve clause: its effect on average salaries, on the remuneration to marginal product, and the premium paid to a player for changing teams. The evidence suggests that introducing the reserve clause reduced average salaries and the premium for changing teams; detectable monopsony power was transferred to team owners almost immediately. However, there was no statistically significant impact of the reserve clause on how much players were paid for their marginal product. The empirical results indicate that reserve clause shifted considerable monopsony power to team owners immediately after it was instituted.
\end{abstract}

JEL Classification Codes: J31, J42, L83

Keywords: Sports economics, monopsony, free agency, negotiation

*This paper is a derivative of Ashcraft's Masters of Arts in Economics thesis written at the University of Texas - Arlington in 2005; Depken was the faculty supervisor. Helpful suggestions by seminar participants at the 2005 Southern Economic Association annual meetings, the 2006 Academy of Economics and Finance annual meetings, Berry College, Kennesaw State University, the University of Texas at Arlington, and West Virginia University are acknowledged. The usual caveat applies.

${ }^{\dagger}$ Burlington Northern-Santa Fe Railway Company, Fort Worth, TX 76131, Office: (817) 352-4919, E-mail: jennifer.ashcraft@bnsf.com

${ }^{\dagger \dagger}$ Craig A. Depken, II, Department of Economics, University of Texas at Arlington, 817272-3290 (office), 817-272-3145 (fax), depken@uta.edu 


\section{Introduction}

Prior to 1974 the professional baseball labor market was characterized by the so-called "reserve clause," which tied a player's services to his current team indefinitely, thereby transferring monopsony power to baseball team owners. The reserve clause was a constant source of friction between players and team owners throughout its history. These frictions were somewhat mitigated by arbitration, introduced in 1974, and free agency, introduced in 1976, both of which essentially removed the reserve clause for all but the least experienced players in the game. These two events have been the focus of a voluminous literature testing how restrictions in the baseball labor market (and their removal) affected several variables, including player salaries, player mobility, and competitive balance, to name a few.

However, professional baseball did not always have a reserve clause. The reserve clause was not formalized until 1887, before which baseball players had varying degrees of freedom in negotiating with other teams. This paper complements the existing literature by analyzing the impact of reserve clause, in its infancy, on the salaries of a select number of players from the 1880s. The paper provides a unique contribution by investigating the other end of the reserve clause time line.

Using a rediscovered data set describing the salaries of several high-quality players from the 1880 s, we estimate the impact of the reserve clause on average player salaries, remuneration to marginal product, and the premium paid to players when changing teams. To do so, we employ a two-step approach. The first entails estimating team revenue and production functions for the decade of the 1880s, from which it is possible to estimate each player's marginal product and marginal revenue product. The second step estimates a wage model, controlling for player marginal product and other variables, to determine what impact the reserve clause had on player salaries and, alternatively, the level of Pigouvian exploitation.

The evidence suggests that the reserve clause did reduce average player salaries, ceteris paribus, but that the reserve clause did not alter the average remuneration that players received for their marginal product. Moreover, it seems that the reserve clause did reduce, but not totally eliminate (at least in its first three years), the premium paid to players for changing teams. In other words, in many ways the reserve clause had the intended impact on player salaries in the period immediately 
after it was formally introduced to the baseball labor market.

As quickly as the removal of the reserve clause allowed salaries to increase, it seems that instituting the reserve clause ninety years earlier had an immediate deleterious effect on player salaries. The results presented here, combined with the results obtained in earlier studies concerning the free-agency period after 1976, strongly support the claims of baseball players and previous academic studies that the reserve clause artificially held down player salaries to the enrichment of team owners, in accordance with economic theory.

\section{The Reserve Clause: History and Literature Review}

The game of baseball began as a sport played by society's elite. Baseball's first organized team was the New York Knickerbockers Base Ball Club, formed in the early 1840s and led by Alexander Cartwright. This team reflected more of a social-club atmosphere rather than the aggressive atmosphere future teams would eventually display. According to Seymour (1960), the Knickerbockers were more genteel in the way they handled the game, "their rules and regulations emphasized proper conduct" (p. 15).

Throughout the 1850s and 1860s, including the Civil War years, baseball became more popular, played exclusively as an amateur sport but in a much more democratic fashion than in earlier times. From 1871 through 1875, the National Association of Base Ball Players, or NABBP, united the Knickerbockers with other club teams (Gillette and Palmer 2004). Its main purpose was keeping the sport at the zero-wage amateur level while maintaining an atmosphere of a "gentlemen's sport." However, as a consequence of the sport's increasing popularity, a professional analogue to the amateur sport eventually emerged.

Despite many objections, the professional era began to take root between the late 1860s and early 1870s. Before 1876, when the still-existing National League formed, there were no restrictions on player movement. However, with the formation of the National League, this would change. According to Sean Lahman, "players had owned the teams and run the games, but the National League was to be run by businessmen. They [team owners] established standards and policies for ticket prices, schedules, and player contracts" (Baseball One Website, 2005). 
As baseball transformed into a business, labor issues soon arose. Unlike present day baseball players, first generation professional baseball players were not compensated as full-time, year-round professional athletes. In fact, management believed players should be employed elsewhere during the off-season months (Seymour 1960, p. 106). However, as teams competed for players, team expenses began to escalate. According to Seymour, "[t]he owners soon realized what was causing high salaries. It was competition among themselves for players. Scrambling for men jacked up payrolls and boosted costs. The owners believed the existence of even the wealthy clubs was threatened" (Seymour 1960, p. 106).

From the owners' point of view, there was an impetus for a system that would enable management to prevent player salaries from increasing. Moreover, owners expressed concern that one or a few teams might monopolize all of the best players, thereby causing a permanent distortion in competitive balance, ultimately threatening the financial wellbeing of the entire league.

As a result, what would eventually become the reserve clause was initiated in 1879 . Intended to decrease expenses by placing limits on player salaries, the policy initially "reserved" only a few players on each team. While a reserved player was tied to one team unless the team owner decided otherwise, it is not clear how well the system was enforced. Anecdotal evidence suggests that the initial reserve system was not as effective as team owners intended. Nevertheless, Burk (1994) described the reserve system as "the most significant step [up to that time] in a progression of moves to limit player independence and control" (p. 63).

During the 1880s two additional leagues were formed: the American Association (from 18821891) and the United Association (for one year in 1884). As the new leagues increased competition for players, in 1883 the American Association and the National League jointly "agreed" to adhere to the reserve clause. Thus, the original reserve system evolved into a gentleman's agreement in which players were included on each team's reserve list by reference only (Spalding 1960), i.e., there were no contract stipulations concerning the reserve clause. This reserve system was more effective but was also somewhat difficult to enforce as there was little recourse if one team "stole" a player from another team. However, starting in 1887 the reserve clause was formally included in player contracts (Spalding, p. 109), making the enforcement of the reserve clause much easier. 
Once it was formalized in 1887, the reserve clause persisted until 1974, when baseball introduced final offer arbitration for players with at least three years of major league experience. While not allowing for unlimited free agency, it did shift some market power to players, although players were still tied to their teams indefinitely. In 1975, Andy Messerschmidt and Dave McNally sued Major League Baseball to become free agents. ${ }^{1}$ After several months of arbitration and court appearances, the two players were granted free agent status for the 1976 season, although only Messerschmidt took advantage. Thereafter, free agency was introduced for players with more than six years of Major League Baseball experience, which expanded the already existing arbitration system. As predicted by economic theory, the shift of market power to the players caused a dramatic increase in the salaries of veteran players, and the clear regime changes in 1974 and 1976 have been the focus of numerous studies concerning salaries, player mobility, and competitive balance.

In the pre-free agency era, the seminal paper concerning the reserve clause was Rottenberg's (1956) theoretical analysis of baseball's labor market. He examined the foundation and effects of the reserve clause and questioned the claim that the reserve clause was needed to prevent higherrevenue teams from dominating the market for high-quality baseball players. Rottenberg argued that teams eventually experience diminishing returns from hiring high-quality players. That is, ticket sales increase at a decreasing rate per "star" player added to the roster. In the pursuit of maximum profits, it is not in a team's best interest to dominate other teams, since "no team can be successful unless its competitors also survive and prosper sufficiently so that differences in the quality of play among teams are not "too great"' (p. 254). Therefore, he concluded that without the reserve clause in place, players would go to where they are valued the most but not necessarily to the richest, or largest market, teams.

In the post-free agency era, several authors have investigated the impact of the reserve clause on player mobility. For example, Maxcy (2002) examined the impact of free agency on competitive balance through its impact on player mobility. Using a logit model to analyze player mobility

\footnotetext{
${ }^{1}$ This was not the first lawsuit concerning free agency. In 1970, Curt Flood, center fielder for the St. Louis Cardinals, sued Major League Baseball after he was involuntarily traded in 1969 to the Philadelphia Phillies. Curt Flood argued that Major League Baseball violated anti-trust statutes and sued for economic damages. Although he ultimately lost his case, it was heard by the U.S. Supreme Court and arguably galvanized players for future action against the reserve clause.
} 
during the sample period 1951-1999, he found that lower transaction costs increased the likelihood of a player transfer. Hylan, Lage, and Treglia (1996) studied the effects of player mobility from 1961 through 1992, focusing solely on pitchers. They concluded that pitchers with over seven years experience did not move as often in free-agency as they had during the reserve clause.

Depken (2002) analyzed player talent concentration before and after free agency using three measures of the concentration of player talent in both pitchers and hitters: runs scored, home runs, and strikeouts. The empirical results suggest that free agency improved the level of concentration for home runs in Major League Baseball, but that, overall, the dispersion of player talent was not dramatically altered after free agency was instituted.

Cymrot, Dunlevy, and Even (2001) studied the earnings of players who were free agents and non-free agents when they moved from one team to another versus staying with their current team. Using current wages and potential wages during the 1979 and 1980 seasons, a two-step Heckman procedure was used to adjust for selection bias. Their results suggested that, whether a player was a free agent or not, player movement was not affected since a player would move to where he was valued the most regardless of who acquired the economic rents.

Levin, Mitchell, Volcker, and Will (2000) argue that competitive balance declined as a result of higher revenue teams attracting better skilled players after free-agency. Depken (1999) found that competitive balance was reduced in the American League after free agency was introduced but that there was no significant improvement in competitive balance in the National League. However, Eckard (2001), using a different measure of competitive balance, found that competitive balance narrowly decreased in the American League but improved in the National League after free agency. Moreover, he concluded that "the bulk of year-to-year variation is explained by factors unrelated to market size" (p. 222).

A number of studies have focused on the impact of free-agency and arbitration on player salaries; in essence testing the extent to which removal of the reserve clause reduced monopsony power. Scully (1974) and Medoff (1976) compared estimated marginal revenue products to the salaries of players during the pre-free agency period. Both found that team owners had significant monopsony power. Sommers and Quinton (1982) found that the first wave of free agents in baseball were paid 
much closer to their estimated marginal revenue product, suggesting that the reserve clause was a binding limitation on player salaries; removing the monopsony power of team owners led to an immediate increase in player salaries. Chelius and Dworkin (1980) were the first to estimate the impact of final offer arbitration (FOA) on salaries and found that FOA eligibility substantially increased player salaries, suggesting that the reserve clause conferred substantial monopsony power to team owners. Marburger (1994) found evidence that monopsony power was not completely eradicated with arbitration but that it was eroded over the years between arbitration eligibility and free-agency eligibility.

The literature focusing specifically on the early period of the reserve clause is very limited. Fort (2005) quite ably reviews and re-positions Rottenberg's insights concerning the broad literature concerning the reserve clause. He undertakes a brief empirical investigation of how the reserve clause impacted competitive balance in the 1880s and finds adverse effects. Eckard (2001) also discusses the early period of the reserve system and provides empirical evidence suggesting that competitive balance was adversely affected by the reserve clause, inferring that the reserve system was a rent-protection scheme on the part of team owners.

\section{The Reserve Clause in its Infancy: Testable Hypotheses}

Consider each player's salary as the outcome of a negotiation between the player, or his representative, and the team, or its representative. The contract zone, or negotiating space, can be defined by two extremes (see Pigou, 1920, Persky and Tsang, 1974, or Faber, 1976). At the lower end is the player's reservation wage, or the minimum salary for which he is willing to play, and at the upper end is the player's marginal revenue product, or the maximum the team is willing to pay. The negotiation process yields an actual salary that can be considered a weighted average of the two extremes of the contract zone, i.e., $w_{i}=\left(1-\alpha_{i}\right) w_{i}^{r}+\alpha_{i} M R P_{i}$, where $\alpha_{i} \in[0,1]$ is an index of negotiating strength on the part of the player, $W_{i}^{r}$ is the player's reservation wage and $M R P_{i}$ is the players marginal revenue product. ${ }^{2}$

As $\alpha_{i}$ approaches one, the player's ability to negotiate for higher wages increases, and as $\alpha_{i}$ ap-

\footnotetext{
${ }^{2}$ This formulation is similar to Marburger (1994).
} 
proaches zero the player's ability to negotiate a wage greater than his reservation wage is curtailed. Anything that influences $\alpha_{i}$ can either increase or decrease the ability of one party to negotiate to their favor. While it is not possible to directly estimate $\alpha_{i}$ for any particular player, it is possible to infer how various player, team, and general market characteristics influence $\alpha_{i}$, on average, through their net impact on player salaries.

Our formulation allows players to have different contract zones because of different reservation wages, different marginal revenue products, and idiosyncratic factors that influence their negotiation strength. Moreover, the same player might have a different contract zone with different teams if their reservation wage, marginal revenue product, and relative negotiating strength varies. The formulation of the negotiated wage used here has the advantage of being flexible in allowing for different equilibrium wage rates for seemingly homogeneous players.

These various influences on the contract zone might make identification of the impact of the reserve clause difficult. However, anecdotal evidence suggests that during the 1880s the limitations might not be as severe as initially feared. First, ticket prices during the period investigated were set by the league and were common for all teams. Therefore, the only differences in marginal revenue product would be in attendance differences. Second, the reservation wages of baseball players were arguably lower and less volatile than in the modern era. ${ }^{3}$ This suggests that the differences in contract zones across players and time may have been associated more with differences in negotiating strength than in differences in reservation wages or the value of marginal product.

Salary data for all players during the 1880s are not available, precluding a direct estimate of the negotiating strength of players and team owners. We can, however, estimate the influence of the binding reserve clause, instituted in the late 1880s, on the salaries of a select group of highquality players. Utilizing an unique data set, our estimation approach allows us to determine the net impact of the binding reserve clause on the negotiating strength of the average player (in the sample), effectively testing whether the reserve clause shifted monopsony power to team owners immediately after its inception.

Three hypotheses about the influence of the reserve clause on player salaries are tested. First,

\footnotetext{
${ }^{3}$ Today's high-quality baseball players have more, and more valuable, alternative sources of income than players in the 1880 s.
} 
did the evolving reserve clause increased monopsony power which would cause an immediate decline in the negotiating strength of all players and therefore a decline in average salaries? This hypothesis is formulated as:

Hypothesis 1 The institution of the reserve clause did not cause a change in average player salaries.

We also test whether the reserve clause reduced the remuneration the average player received for his marginal product. We compare the return to marginal product during the non-reserve clause period of the sample with the return to marginal product after the binding reserve clause was instituted. The second hypothesis is formulated as:

Hypothesis 2 The institution of the reserve clause did not cause a change in the remuneration to player marginal product.

The third hypothesis follows from the Rottenberg (1956) conjecture that the reserve clause would allow team owners to distribute amongst themselves the rents generated by a player, thereby reducing the premium paid to a player when they changed teams. The third hypothesis is formulated as:

Hypothesis 3 The institution of the reserve clause did not cause a change in the premium paid to players when changing teams.

To test these hypotheses, we estimate a wage model in which we control for player characteristics (including quality), characteristics of the market for baseball labor, and characteristics of the overall economy in order to isolate, to the extent possible, the influence of the reserve clause on the variables of interest. Specifically, we control for the player's major league experience up to the current year, and its quadratic, whether the player changed leagues, and whether the player was a non-pitcher. A player's experience might enhance his negotiating stance with team owners as his value is revealed to team owners over time. The turnover of teams and leagues during the early history of professional baseball was rapid, therefore it is like that when a player changed leagues he did so at a reduced 
salary. Because there were many more position players than pitchers, it is likely that the average salary for non-pitchers was lower than for pitchers.

An alternative to directly estimating the impact of the reserve clause on player salaries is to estimate the impact of the reserve clause on the the amount of "exploitation" in the baseball labor market. While this term is often associated with Marxist discourse, A. C. Pigou (among others) used the term in his discussion of how the marginal product of labor might diverge from its real wage (Pigou, 1920). ${ }^{4}$ In his discussion, Pigou was careful to point out that exploitation was not just a normative issue; market forces not associated with class might cause a divergence in real wages from real marginal product (see Pigou, 1920, Part III, Chapter XIII). ${ }^{5}$

Both approaches are taken, although the qualitative results are not different and inference is perhaps stronger using the level of exploitation. We associate various player characteristics, interventions in the baseball labor market, the overall level of macro-economic activity, and team characteristics, with the expected negotiating strength of players and team owners. Anything that increases (decreases) the negotiating strength of the players would be expected to cause a net increase (decrease) in player salaries, ceteris paribus.

\section{Data, Model Specifications, and Empirical Results}

The empirical analysis of player salaries necessarily requires a measure of each player's marginal product. Only after controlling for the player's quality is any accurate inference about the impact of the reserve clause on player salaries possible. In order to determine each player's marginal revenue product, we follow the two-step approach pioneered by Scully (1974) and utilized by numerous other authors. The first step entails estimating a team revenue as a function of team quality, reflected in winning percentage, and year, city, and league fixed effects. This equation provides a

\footnotetext{
${ }^{4}$ Scully (1974) uses the term in his seminal analysis of professional baseball salaries before the removal of the reserve clause.

${ }^{5}$ Persky and Tsang (1974) analyzed the level of Pigouvian exploitation in the U.S. economy, relating the ratio of marginal product to real wages as a function of unionization, unemployment, inflation, the capital stock, and government imposed controls in the labor market. Using a time series of macroeconomic data, they found evidence that the level of exploitation increased with unemployment, inflation, the capital stock, and governmental intervention. The only covariate that was negatively correlated with exploitation was the level of unionization. Using a cross-section of U.S. industries they found confirmatory evidence that unionization was negatively correlated with exploitation. In our approach we include several independent variables analogous to Persky and Tsang.
} 
rough estimate of the value of an additional point of winning percentage (on a scale of zero to one thousand) to the team owner. The second step entails estimating a team production function where output is team winning percentage and the primary inputs are team offense and defense. After estimating the team production function, the contribution of a player to team winning percentage can be calculated. This generated regressor is included in the second stage of the analysis wherein player salary (or rate of exploitation) is related to marginal product, player characteristics, and general market characteristics.

The salary data employed in this analysis were obtained from an article published in 1914 in the now-defunct magazine $Y Y$. Penned by Mr. ABC, this short article titled "XXX," lists the salaries of twenty-nine high-quality players from 1881 through 1889. The article discusses the salary issues during the 1880s, and points out that concerns over escalating baseball salaries in the 1910s were similar to those in the 1880s. Mr. ABC does not mention the reserve clause and its impact on player salaries, but rather questions whether salaries are "too high" for the best players in the league. ${ }^{6}$

We combine ABC's data, assuming that any errors are purely random, with the wealth of historical statistics gathered by baseball historians over the past several decades. The data provide a unique opportunity to test the influence of the reserve clause during its inception rather than the more common approach of testing the influence of removing the reserve clause after 1976.

\section{A. Estimating Player Marginal (Revenue) Product}

Following Scully (1974), we estimate a team attendance (revenue) function:

$$
D E P_{i t}=\gamma_{0}+\gamma_{1} W I N P E R_{i t}+\phi T E A M+\theta L E A G U E+\tau T I M E+v_{i t},
$$

where $D E P_{i t}$ is, alternatively, annual home game attendance or annual real total revenues for team $i$ in year $t$, and $v_{i t}$ is a zero mean heteroscedastic error structure that is tested for first order autocorrelation. The explanatory variables include the winning percentage of team $i$ in year $t$ (WINPER $R_{i t}$ ), a matrix of team fixed effects (TEAM), a matrix of league fixed effects

\footnotetext{
${ }^{6}$ Note to editors and referees: Our data source will be revealed and raw data reported in an appendix upon publication.
} 
$(L E A G U E)$, and a matrix of year fixed effects $(T I M E)$. Real total revenue is calculated as team home attendance times $\$ 0.50$ adjusted to reflect 2004 dollars. ${ }^{7}$

The results from estimating equation (1) provide evidence of the additional attendance or dollars in revenue from an additional point in winning percentage. Winning percentage is, in turn, the outcome of player defensive and offensive performance, managerial decisions, and idiosyncratic influences such as player injuries, team cohesion, and weather. The value of a player is therefore indirectly connected to team attendance or revenue through the player's contribution to team winning; players contribute to team winning percentage through their offensive and defensive contributions. Field position players provide defensive output in the form of fielding, assists, and put-outs, and offensive output in the form of hits, stolen bases, and sacrifices. Pitchers contribute through stikeouts, innings pitched, reduced numbers of earned runs allowed, and, to a lesser extent, the offensive and defensive contributions of regular field players. While a large literature has investigated various team-level production functions, using various functional forms and inputs, we follow the approach by Scully (1974) and use two team-level measures of offensive and pitching performance: slugging average and team strikeout-to-walk ratio, respectively.

The estimated production function is specified as:

$$
\begin{aligned}
W I N P E R_{i t}= & \beta_{0}+\beta_{1} T S A_{i t}+\beta_{2} T S W_{i t}+\beta_{3} C O N T_{i t}+\beta_{4} O U T_{i t}+\beta_{5} N L_{i t}+ \\
& \beta_{6} U A_{i t}+\epsilon_{i t},
\end{aligned}
$$

where the $\beta$ 's are parameters to be estimated and $\epsilon_{i t}$ is a composite zero-mean heteroscedastic error term. The dependent variable is team win percentage, which normalizes team performance by the number of games a team played; games played varied during the sample period. The independent variables include the the team slugging average (TSA), team strikeout-to-walk ratio (TSW), a dummy variable that takes a value of one if the team finished the season within five games of first

\footnotetext{
${ }^{7}$ Total home game attendance were collected from The Baseball Encyclopedia. In general, team prices are not available from this era however the National League agreed to fix gate prices at $\$ 0.50$ in 1879 . The price of attendance to National League baseball games played in the Polo Grounds in New York was fifty cents for the 1903, 1904, 1905 and 1906 baseball seasons (New York Times, various editions). We assume that the other teams in the other leagues charged the same price as the National League. It is possible teams in other leagues charged different prices, but a careful search of the existing documentation does not reveal any differences and suggests that ticket pricing was determined by the league rather than the team.
} 
place (CONT), a dummy variable that takes a value of one if the team finished more than twenty five games out of first place (OUT), a dummy variable that takes a value of one if the team played in the National League (NL), and a dummy variable that takes a value of one if the team played in the United Association (UA). ${ }^{8}$

The top panel of Table 1 presents the descriptive statistics for the team data employed in estimating equations (1) and (2). The average attendance for teams during this period was approximately 106,000 and average real gate revenues were approximately $\$ 980,000 .{ }^{9}$ The average winning percentage is less than 500 because only teams that played more than fifty games in a season are included in the sample. The average team slugging average was 336 and the average strikeout-to-walk ratio was 2.09. Approximately $20 \%$ of the teams in the 1880 s finished the season within five games of first place whereas approximately $46 \%$ finished the season more than 25 games out of first place.

Table 2 reports the estimation results of two versions of equation (1): the first uses attendance as the dependent variable, the second uses real gate revenues. Model (1) in Table 2 indicates that a one point change in team winning percentage correlated with approximately 190 additional fans in attendance. On average, National League teams enjoyed attendance on par with the American Association, however the United Association enjoyed substantially lower attendance. Over the period of the sample, attendance to the average major league baseball team increased almost five-fold, as can be seen by the parameters on the year specific time effects. Model (4) in Table 2 suggests that a one point change in team winning percentage was worth, on average, approximately 1,750 2004 dollars. Consistent with the attendance model, National and American League teams enjoyed parity in revenue, however the United Association enjoyed dramatically lower revenues, on average. ${ }^{10}$ The increasing popularity of professional baseball and the general prosperity during this period led to a dramatic increase in the real revenues professional baseball teams generated.

The remaining models in Table 2 control for heteroscedasticity across teams (Models 2 and

\footnotetext{
${ }^{8}$ Slugging percentage is defined as the total bases obtained by the team divided by the total number of at-bats. Team and player data were obtained from www.baseballreference.com, last accessed February 2007.

${ }^{9}$ Teams in the $1880 \mathrm{~s}$ did generate some additional revenue through concession sales. However, at the time there were no media, merchandise or stadium revenue, nor was there league revenue sharing. We do not anticipate the measurement error in our estimate of real total revenue to prove debilitating to the estimation results reported herein.

${ }^{10}$ This might explain why the United Association only survived for the single year of 1884 .
} 
4) and also autocorrelation (Models 3 and 5) using a Panel GLS estimator. In each case, the qualitative results are retained, suggesting that failing to accommodate potential heteroscedasticity and/or autocorrelation is not an underlying source of spurious results. When necessary, we use the estimation results from Model (4) to calculate an estimate of a player's marginal revenue product.

The results in Table 2 can be used to estimate the value of marginal product, either in terms of attendance or real revenue, once the production function has been estimated. Table 3 reports the results from estimating equation (2) using three different panel estimators. Model (1) uses a random effects estimator. The data, however, display slight but statistically significant heteroscedasticity. Therefore, we estimate the production function using a panel GLS estimator with heteroscedastic panels but without any autocorrelation; these results are reported in Model (2) in Table 3. The final specification allows for a common $\mathrm{AR}(1)$ parameter. The results for these three specifications are largely consistent with each other. The estimated common $\operatorname{AR}(1)$ term is 0.085 , suggesting there is not a large year-to-year connection in team production. Moreover, the results in Model (3) are based on 15 fewer observations as the teams that played more than fifty games in the single season of the United Association are dropped. We therefore utilize the results from Model (2) in Table 3.

The marginal win percentage associated with a one unit change in team slugging average is approximately 1.08, whereas a one one-hundredth improvement in team strikeout-to-walk ratio corresponds to an approximate 0.24 improvement in team win percentage (team winning percentage being measured on a zero to one-thousand scale). Teams out of contention fared approximately 125 percentage points worse than teams with comparable offensive and defensive statistics but were not out of contention, suggesting that being out of contention might reduce team spirit, "hustle," or motivation (consistent with Scully, 1974). On the other hand, teams in contention performed about 105 percentage points better, ceteris paribus. Finally, teams that played in the National League were relatively worse, ceteris paribus, suggesting that the National League had a relatively higher standard of play, also consistent with Scully (1974). Finally, teams in the United Association, which was in existence for only one year, were not significantly different than American Association teams at the time. 
The team production function is used to calculate the marginal product of the players in the sample. ${ }^{11}$ Using the results from Column 3 of Table 4, each player's marginal win percentage is calculated as

$$
M W P_{i t}=\left(1000 \times S P_{i t} \times P E R A B_{i t} \times 1.083183\right)+\left(100 \times S W_{i t} \times P E R S O_{i t} \times 0.2447136\right),
$$

where $S W_{i t}$ is set to zero for non-pitchers.

The Scully approach is not immune from criticism. The approach is "proportional," in that it "credits the player with some proportion of his individual performance" (Krautmann, 1999, p. 371), whereas Zimbalist (1992) recommends an "incremental" approach which measures the change in a team's performance with and without a player. While Scully relies upon estimated revenue functions to indirectly determine marginal revenue product, Krautmann (1999) recommends utilizing a welloperating free-agent market to provide a direct estimate of marginal revenue products. Krautmann's approach is the least demanding in terms of data and avoids potential specification errors; all that is required is player salaries and widely disseminated player statistics. On the other hand, the approach assumes that the free-agent market for players is sufficiently competitive to erode all monopsony power, which was unlikely during the period investigated herein. Furthermore, while Krautmann avoided estimating MRP for pitchers, the Scully approach provides an estimated marginal product for pitchers. ${ }^{12}$

There is also a debate as to whether the strikeout-to-walk ratio is an appropriate measure of pitcher contribution; some authors have instead used earned run average. However, as Bradbury (2005) has shown, the ERA is vulnerable to influences beyond the control of the pitcher and is not highly correlated from year to year. This suggests that the ERA is not an ideal measure of a pitcher's marginal contribution to team success. Using the Scully methodology assures nonnegative marginal products and arguably better captures the contribution of a pitcher to his team's

\footnotetext{
${ }^{11}$ See the appendix for an extended discussion on exactly how to calculate a player's marginal product using the Scully approach.

${ }^{12}$ Krautmann did not investigate the MRP of pitchers arguing that pitchers in the modern era are often specialists, i.e., starters, closers, or set-up men, and therefore the appropriate measure of a pitcher's productivity is not nearly as clear as for position players. Moreover, the Krautmann approach would sacrifice $40 \%$ of our sample, which seems excessive given its already limited size.
} 
success. ${ }^{13}$

Several representative players are listed in Table 4 including their nominal and real salary, their production statistics, and their estimated marginal win percentage. ${ }^{14}$ It is clear that estimated MWPs vary across players and player-types, i.e., pitchers and non-pitchers. The descriptive statistics for the marginal win percentage for the entire sample of players are provided in the lower panel of Table 1; the minimum win percentage calculated in the sample was attributed to James Ryan in $1885(\mathrm{MWP}=1.85)$ and the maximum contribution was attributed to Charley Radbourn in 1883 $(\mathrm{MWP}=154.71)$.

According to economic theory, the marginal win percentage of a player is a factor in the negotiation of a player's salary. The player's marginal product is one of the components of the player's marginal revenue product, the upper end of the contract zone. The greater the player's marginal product, the greater should be the player's negotiating strength, viz-a-viz other players in the league. Moreover, high-quality players have a more credible threat of shirking and reducing productivity if a satisfactory salary is not negotiated.

However, the marginal product of a player is not known until after the season is completed, whereas the player's salary was (and is) typically determined at the beginning of the season. We assume that a player's previous season's marginal win percentage (marginal product) is a rational proxy for the marginal win percentage in the current year. Therefore, in the second stage of the analysis, the once-lagged marginal win percentage for players (when available) is used as a proxy for the anticipated marginal win percentage in the current year.

\section{B. Estimating the Impact of the Reserve Clause on Player Salaries}

To test whether the binding reserve clause influenced real player salaries as hypothesized in the

\footnotetext{
${ }^{13}$ Pitchers in the 1880 s were less specialized than in the modern era. Furthermore, including ERA and other pitching statistics directly into the team production function yields negative marginal products for numerous players.

${ }^{14}$ To calculate the marginal attendance or the marginal revenue product of each player's contribution, multiply the MWP by the appropriate parameter estimate from Table 2. However, in the subsequent analysis, we use the marginal product rather than marginal revenue product as the two different measures differ only by a scale effect and would not fundamentally alter the regression results.
} 
previous section, various wage models are estimated. Their general functional form is:

$$
\begin{aligned}
\text { DEP }_{j t}= & \delta_{0 j}+\delta_{1} M W P_{j t-1}+\delta_{2} \text { Experience }_{j t}+\delta_{3} \text { Experience }_{j t}^{2}+\delta_{4} \text { NewTeam }_{j t} \\
& +\delta_{5} \text { NewLeague }_{j t}+\delta_{6} \text { NonPitcher }_{j t}+\delta_{7} \text { MacroIndex }_{t}+\phi^{\prime} X_{j t}+\theta^{\prime} T_{j t}+u_{j t},
\end{aligned}
$$

where $j$ indexes players, $t$ indexes time, $u_{j t}$ is a zero-mean composite error term, and the $\delta$ 's and the vectors $\phi$ and $\theta$ are parameters to be estimated.

The dependent variable is either the player's salary converted to 2004 dollars using the Bureau of Labor Statistics Consumer Price Index, the natural logarithm of the player's real salary, or the ratio of a player's estimated real marginal revenue product (using the results from the revenue equation in Table 2) to his real wage. ${ }^{15}$

The explanatory variables include the once-lagged marginal product $(M W P)$, the player's experience and its quadratic (Experience, Experience ${ }^{2}$ ), whether the player changed teams during the previous off-season (NewTeam), whether the player changed leagues during the previous offseason (NewLeague), and a dummy variable that takes a value of one if the player was a non-pitcher (NonPitcher). Rather than include a simple time trend or year dummy variables to control for inter-temporal issues common to all players, we include the NBER's U.S. Index of Manufacturing Production (MacroIndex) to control for macroeconomic effects common to all players but which might have influenced player salaries (specifically their reservation wage) during the sample period. ${ }^{16}$

The remaining explanatory variables are included in $X_{j t}$ and control for the impact of the reserve clause after its inception in 1887. To test for the influence of the binding reserve clause, a dummy variable $(R C)$ was created that takes a value of one for the years 1887-1889. To test Hypothesis 1 in the previous section, we include the $R C$ dummy variable as a separate regressor. If the reserve clause reduced the negotiating stance of the players in the sample, on average, we anticipate a negative parameter estimate on this variable. To test Hypothesis 2 in the previous

\footnotetext{
${ }^{15}$ There are potentially negative effects of using a ratio as the regressand (see Kronmal, 1993, for example), including possible specification bias. On the other hand, any measurement error in the estimated real marginal product is shifted to the left hand side of the estimating equation, where it is expected to only influence the efficiency of the estimates.

${ }^{16}$ We acknowledge Brad Humphreys for this valuable suggestion. During the sample period there were two peaks (March 1882 and March 1887) and two troughs (May 1885 and April 1888) in the business cycle.
} 
section, the dummy variable $R C$ is interacted with the player's estimated MWP. If the reserve clause reduced the remuneration to quality on the margin we anticipate a negative parameter estimate on this interaction. Finally, to test the Rottenberg (1956) conjecture, Hypothesis 3 in the previous section, we interact the $R C$ dummy variable with NewTeam. If the binding reserve clause shifted the allocation of rents to being between owners rather than being between owner and player, we anticipate a negative parameter estimate on this variable.

Equation (3) is a reduced form model in which the parameter estimates indicate which covariates convey more negotiating power to owners, which would be reflected in a negative parameter estimate, or to players, which would be reflected in a positive parameter estimate. It is anticipated that greater marginal product in the previous season, greater levels of experience, greater outside opportunities (as reflected in an expanded macro-economy), and moving to a new team all improve the negotiating stance of the player, ceteris paribus. Therefore. we anticipate positive coefficients on these variables. On the other hand, the supply of non-pitchers was considerable larger than pitchers (even at this early point in baseball history) and therefore the negotiating stance of nonpitchers is expected to be worse relative to pitchers. ${ }^{17}$ Moreover, moving to a new league was likely to reduce the negotiating stance of the player or at least the rents they could expect to extract from the team owner. For these two variables we anticipate non-positive parameter estimates.

When the dependent variable is the ratio of the player's estimated marginal revenue product and his wage rate, the expected signs are reversed, e.g., if the reserve clause reduced the ability of the player to negotiate we expect a positive parameter on this variable. To estimate a player's marginal revenue product, the player's marginal win percentage is multiplied by 1,752 (obtained from Model (4) of Table 2).

The bottom panel of Table 1 presents the descriptive statistics of the data used to estimate equation (6). During the sample period the average nominal salary was $\$ 2,461(\$ 45,872$ in 2004 dollars). Because the players in the sample were amongst the best players of the day, it is likely that the sample average is greater than the overall Major League average salary. The average MWP for all players was 57 points. The average player in the sample had 5.8 years of experience,

\footnotetext{
${ }^{17}$ In other words, the elasticity of supply of position players is expected to be greater than the elasticity of supply of pitchers.
} 
approximately 18 percent of the observations correspond to a player that switched teams from one season to the next, approximately 3 percent of the observations corresponded to players that switched leagues from one season to the next, and 60 percent of the observations corresponded to non-pitchers. Approximately 43 percent of the sample observations correspond to the period during which the binding reserve clause pertained. Finally, the NBER manufacturing index $(1909-1913=$ 100) averaged 33.274, but did show a considerable range during the sample period.

The interaction terms are included in the $X_{j t}$ vector in equation (3). The $\delta_{0 j}$ measure playerspecific unobserved or unmeasured heterogeneities that might influence the outcome of the playerteam salary negotiation. Because the sample reflects only a subset of the players in the major leagues at the time, the player-specific effects are treated as random effects. Table 5 reports estimation results in which only player-specific effects are included, i.e. restricting $\theta=0$. Table 6 and Table 7 report estimation results including player and team specific effects, the latter reflecting team-specific premia paid to players during the sample period.

\section{The Reserve Clause and Player Salaries: Empirical Results and Discussion}

Consider first the more conservative results presented in Table 5. Model (1) in Table 5 is a base model which includes no controls concerning the reserve clause; the dependent variable is real salary in 2004 dollars. Given the limited sample size and its historical nature the results are encouraging; the estimated parameters have the expected sign and are generally statistically significant. The average player was paid more as he was more productive, suggesting that players were able to extract some of the value they created for team owners. Players were paid more with more experience, although at a decreasing rate. Players were paid a premium when changing teams but sacrificed salary when changing leagues. The marginal product of non-pitchers was compensated slightly less than the marginal product of pitchers, although the parameter estimate on NonPitcher is not distinguishable from zero. Finally, real salaries were positively related to the the NBER manufacturing index.

The results in Model (1) of Table 5 provide a benchmark with which to compare the specifications that control for the binding reserve clause: Model (2), Model (4), and Model (6) include 
only the $R C$ dummy variable, whereas Model (3), Model (5), and Model (7) include both the indicator variable and its interactions with $M W P$ and NewTeam. Models (2)-(5) use real salary or its natural logarithm as the dependent variable; Models (6)-(7) use Pigouvian exploitation as the dependent variable.

As can be seen in the first row of Table 5, the binding reserve clause had a consistently negative effect on the average salaries of players in the sample, regardless of whether salary was measured in real dollars or natural logarithms. From the specification with real wage as the dependent variable, the reserve clause might have reduced real wages between $\$ 3,000$ and $\$ 5,000$, ceteris paribus. The negative influence of the reserve clause is supported by the specifications that use the log of real salary as the dependent variable; the reserve clause corresponded with a reduction of salaries in the sample by $10 \%$, ceteris paribus. The models in which exploitation is the dependent variable provide a consistent story: after the binding reserve clause was instituted, the ratio of real marginal revenue product and real wages increased, suggesting a reduced negotiating stance for the players in the sample. However, the players in this sample were all high-quality, and intramarginal; therefore, it is likely that lower-quality players were also immediately adversely affected by the reserve clause.

The results in Table 5 suggest there was not a significant impact of the reserve clause on the marginal remuneration for player quality, as reflected in estimated marginal product. In both cases, the interaction between $M W P$ and the $R C$ dummy variable are insignificant, suggesting that the impact of the reserve clause did not change the negotiating strength of players in this dimension. We do not include the marginal win percentage on the right hand side of the specifications using exploitation as the dependent variable. ${ }^{18}$

The interaction between the NewTeam and $R C$ variables tests the Rottenberg conjecture that after the reserve clause the premium paid to a player for switching teams would fall as the rents generated by the player were more so distributed between the two team owners. The results in Table 5 strongly support the Rottenberg conjecture. In Model (3), switching to a new team after the reserve clause was instituted had an approximately $\$ 5,500$ lower premium than before the reserve

\footnotetext{
${ }^{18}$ We experimented with including the $M W P$ on the right-hand side of the specifications using exploitation as the dependent variable. In general, the parameter estimates were positive, suggesting that better players were exploited more so than less skillful players. Moreover, the interaction of $M W P$ with $R C$ was consistently positive, suggesting that better players were exploited more, relative to lower skill players, after the binding reserve clause.
} 
clause. From Model (5), moving to a new team after the binding reserve clause corresponded with an $18.5 \%$ lower salary, on average, than before the binding reserve clause. Combining the parameters on NewTeam and NewTeam $\times R C$, the premium for moving to a new team was only $8 \%$ after the reserve clause rather than $23 \%$ before the reserve clause; this suggests the reserve clause had a dramatic impact on the salaries to those players who moved from team to team, exactly as hypothesized by Rottenberg (1956).

Indeed, the extreme version of the Rottenberg conjecture would have all rents generated by the player being distributed between the team owners involved; the player himself would receive nothing more than his reservation wage, i.e. the sum of the parameters on NewTeam and NewTeam $\times$ RC should be zero. In our sample, this is not the case. However, it should be remembered that the players in this sample are intramarginal. A weaker version of the Rottenberg hypothesis might be applicable here whereas with a sample including lower quality players, the stronger form of the Rottenberg conjecture might be appropriate.

The influence of the reserve clause on the premium paid to players for changing teams is confirmed by Model (7), which uses exploitation as the dependent variable. The positive parameter estimate suggests that after the reserve clause was instituted a player who was traded to another team saw their level of exploitation increase. The sum of the parameter estimates on NewTeam and NewTeam $\times R C$ in Model (7) is not statistically different from zero. Therefore, the reserve clause might have completely eroded the increased negotiating strength a pre-reserve clause player enjoyed when negotiating with an owner of a different team. This is exactly what team owners intended, and is exactly what Rottenberg hypothesized about the operation of a reserve-clause based baseball labor market.

While the results in Table 5 are encouraging and in many ways seem conclusive given the limited scope of the data sample employed, there are at least two potential areas of concern. First is a concern of sample selection. Obviously the sample we have is highly selective but on criteria not made clear by the original provider of the salary data. Were players chosen because of their fame and name recognition? Were players not necessarily chosen but rather teams? Perhaps some teams were more forthcoming with their salary information than others. 
In one attempt to control for selection bias, we used whether the player was of foreign birth, whether the player was from the Southern United States, and whether the player was in the top ten in terms of home runs, runs scored, or earned run average, to identify whether the player's salary was reported. The results were completely unreliable. The large number of players in professional baseball compared to the limited number of players whose salaries were reported overwhelmed the selection model. In another approach, we controlled for possible selection bias based on the teams for which salaries were reported. We used the age of the franchise and the state in which the franchise played to identify selection. The inverse Mills ratio was consistently insignificant, suggesting that selection bias (at least based on the identification employed) is not a significant problem.

Another concern is potentially omitted variables, from both the supply and demand sides. Although the specifications in Table 5 include player-specific effects, which control for unobserved player-specific heterogeneity, there might be concerns that team-specific or city-specific effects have been excluded. Table 6 and Table 7 report estimation results that address this problem. Specifically, we ask a little more from the 200 observations and include 12 team fixed effects (Buffalo, from the National League, is the reference team),

Table 6 reports the estimation results having included the team fixed effects. By including the team specific effects, our estimation results are weakened somewhat. The impact of the reserve clause on average salaries (average level of exploitation) is still negative (positive), consistent with the results in Table 5. However, the impact of the reserve clause on the amount players were paid for the marginal product increases after the reserve clause (significant at the $10 \%$ level) in the specification using real wages as the dependent variable, but is insignificant when using the log of real salaries as the dependent variable. The statistical significance of the interaction between $N e w T e a m$ and $R C$ is lost when including the team fixed effects. While the parameters carry the same sign, although not the same magnitude, the standard errors are considerably larger than when the team fixed effects are restricted to zero. This suggests that some of the reduced premium for changing teams reported in Table 5 might have been caused by the teams involved with the trades. The remaining parameters are all of the same sign, magnitude, and significance as before. 
Table 7 reports the team-specific fixed effects, which reflect additional real wages teams paid players relative to the reference team, ceteris paribus. Any differences in the team fixed effects are reduced form and therefore reflect both demand and supply-side effects, including differences in the costs of living, differences in reservation wages for playing in a large city (perhaps through the "microscope effect"), or a weak negotiating stance on the part of the team owners in these cities is not identifiable. ${ }^{19}$

Looking at the estimated team-specific effects, an interesting pattern emerges. First, almost all of the teams in the sample paid a premium over the reference team of Buffalo; the exceptions are Providence and Indianapolis and the greatest premiums were paid by (in descending order) Washington, New York of the American Association, New York of the National League, and Boston. ${ }^{20}$ This suggests city size might be an important factor to the premium a player received during the 1880s. Table 7 reports the population rank of the team's host city for 1880 and $1890 .{ }^{21}$ Indeed, there is a slight positive correlation between the population rank of the city (low number indicating a greater population) and the premium paid to the average player ( $\rho=-0.36$ in both 1880 and 1890). Figure 1 shows a scatter plot of the estimated team premiums from Model (3) in Table 7 against the population rank of the host city in 1890. There is a negative relationship between the two, although there are exceptions to the general rule such as Detroit, which seems to have paid considerably more than teams in larger cities, and Chicago, which seems to have underpaid relative to teams in smaller cities.

\section{A Conjecture about the Political Economy of the Reserve Clause}

The team fixed effects from Model (6) and Model (7) suggest that Buffalo, Indianapolis, New

\footnotetext{
${ }^{19}$ The "microscope effect" occurs when a player demands a premium for playing in a city in which he will receive considerably more attention and scrutiny. Some players demand a compensating differential for the additional pressure such scrutiny entails. This is arguably one component to the inflated salaries for modern-era players in New York and Boston, for instance. Whether the microscope effect would have pertained to professional baseball in the $1880 \mathrm{~s}$ is not clear. Newspaper accounts of the day do not focus much on the off-field behavior of players and there is virtually no mention of baseball players during the off-season.

${ }^{20}$ Anecdotal evidence suggests that teams in New York, Boston, and Baltimore (the closest team to Washington between 1972 and 2005) all pay substantial premiums to players. Examples include Sammy Sosa playing for the Baltimore Orioles, Alex Rodriguez playing for the New York Yankees, and Manny Ramirez playing for the Boston Red Sox. All of these players were alleged to have received considerably more for their quality of play than expected.

${ }^{21}$ Population counts were obtained from the U.S. Census Bureau.
} 
York (in the American Association), and Providence exploited their players in a statistically similar fashion, i.e., the relative net bargaining power of the team owners to their specific players was about the same, ceteris paribus. Moreover, these four teams were consistently able to exploit their players to a greater degree than the other teams in the sample, as reflected in the negative parameter estimates for the other teams in Model (6) and Model (7).

When the binding reserve clause was passed in 1887 there were 19 teams in the National League and American Association. Among the thirteen teams in our sample, only Troy and Buffalo were out of business by 1885 (two years before the reserve clause was instituted). This suggests that there was a small group of team owners who were able, on average, to pay players considerably less than other teams, ceteris paribus, whether through negotiating savvy or other compensating differentials. If the parameter estimates are accurate, it would seem that there was a majority of team owners who would have voted in the affirmative for the reserve clause not only to improve their own negotiating stance vis-a-vis players but to also erode whatever competitive advantage a minority of other team owners might have had, at least in negotiating salaries. This resembles a "raising rivals' costs" strategy and suggests that there might have been more than just owner-player tensions underlying the reserve clause. Much more evidence is required to support this conjecture: the findings in this paper alone do not seem strong enough to do more than hint at this possibility.

However, we did attempt the following. We dropped the team fixed effects for Indianapolis, New York in the American Association, and Providence, as they were not statistically different from the reference team Buffalo. For the remaining teams in business after the reserve clause we interacted the team fixed effect with the Reserve Clause dummy variable. We then re-estimated equations (6) and (7) including the team fixed effects and their Reserve Clause interactions. In essence, this approach provides a first-pass test for whether, after the reserve clause, those teams that were relatively worse at negotiating were "better" after the Reserve Clause. For five teams the parameter on the interaction of the team fixed effect and the Reserve Clause dummy variable was positive. Of the five positive parameter estimates, four were statistically different from zero. On the other hand, for only Pittsburgh in the National League was the parameter estimate on the 
interaction term negative and significant. ${ }^{22}$ In our sample of player salaries, those team owners who were relatively worse negotiators before the reserve clause became better negotiators after the reserve clause, essentially eroding any competitive advantage a minority of other owners enjoyed.

\section{Conclusions}

This paper provides the first empirical analysis of how the institution of the reserve clause in professional baseball impacted professional baseball player salaries. Prior to 1883, baseball players were essentially free-agents, whereas from 1883-1886 an informal "gentleman's agreement" reserve clause was in effect. Team owners quickly realized that the voluntary reserve clause was not enforceable and had no binding impact on player salaries or movement. Therefore, starting with the 1887 season, the reserve clause was formalized in player contracts, ostensibly cementing team owner monopsony power. The implementation of the reserve clause in professional baseball provides a natural experiment with which to test whether player salaries, and negotiating stances in general, responded consistent with a shift of monopsony power to team owners.

The literature focusing on the removal of the reserve clause in 1976 is widespread; however. data limitations seem to have precluded any analysis of the other end of the reserve-clause time line. This paper addresses this gap in the literature and essentially closes the loop on the impact of the reserve clause on player salaries. The received literature has shown that the repeal of the reserve clause led to an almost instantaneous increase in player salaries. This study shows that when the reserve clause was instituted player salaries were almost immediately, and adversely, affected.

Assuming that player salaries are the outcome of a simple negotiation process and that the reserve clause altered the relative negotiating stance of players and team owners, three straightforward hypotheses about the impact of the reserve clause are developed. First, the reserve clause would be expected to reduce average salaries, ceteris paribus. Second, the reserve clause might reduce the remuneration to marginal product. Finally, the reserve clause might reduce the premium paid to players for changing teams, a hypothesis initially proposed by Rottenberg (1956) and tested after the reserve clause was repealed but, to date, not investigated when the reserve clause was

\footnotetext{
${ }^{22}$ Results available from the authors upon request.
} 
instituted.

Using a unique data set describing the salaries of 29 high-quality players from 1881 through 1889, these three hypotheses are tested using the two-step approach pioneered by Scully (1974). First, team attendance and revenue functions are estimated to determine the marginal attendance or real dollar revenue associated with a one unit increase in team winning percentage. Second, team production functions for the decade of the 1880s are estimated, from which it is possible to calculate the marginal win percentage contributed by each player's inputs. The marginal win percentage is combined with other player characteristics and general baseball labor market characteristics to test whether the imposition of the various stages of the reserve clause caused a deleterious effect on player salaries. We combine a player's marginal win percentage with the estimated marginal revenue of win percentage to calculate calculate a measure of Pigouvian exploitation (Pigou, 1920), the ratio of real marginal revenue product to real wages. The rate of exploitation allows us to more directly test whether the reserve clause influenced the outcome of the negotiation process in favor of team owners or players.

Despite the limited sample size, potential sample selection issues, and potential measurement errors, the results are encouraging. We find that the reserve clause had an immediate economically and statistically significant negative impact on the average salary in the sample, suggesting that the reserve clause immediately shifted monopsony power to team owners. On average, the intramarginal player salaries in the sample fell by $10 \%$, ceteris paribus, suggesting that lower quality players might have suffered similar if not worse outcomes. We do not find evidence that the reserve clause reduced the remuneration to players for their marginal product. However, we find strong evidence that the reserve clause reduced the premium paid to players for changing teams, lending support to the Rottenberg (1956) conjecture that the reserve clause allowed team owners to redistribute player rents among themselves.

The results reported here are consistent with the reserve clause shifting considerable monopsony power to baseball team owners immediately after its inception, the exact opposite of what happened in 1976 when the removal of the reserve clause almost immediately shifted detectable market power back to the players. 


\section{References}

Bradbury, John Charles (2005). "Does The Baseball Labor Market Properly Value Pitchers?" mimeo, Sewanee: The University of the South, accessed January 2006 at http://bradbury . sewanee.edu/pitchervalue.pdf.

Burk, Robert F. (1994). Never Just a Game: Players, Owners, and American Baseball to 1920, Chapel Hill: The University of North Carolina Press.

Chelius, James R. and James B. Dworkin (1980). "An Economic Analysis of Final-Offer Arbitration as a Conflict Resolution Device," Journal of Conflict Resolution, 24, 293-310.

Cymrot, Donald J., James A. Dunlevy, and William E. Even (2001). "Who's on first: An empirical test of the Coase Theorem in baseball," Applied Economics, 33, 593-603.

Depken, Craig A. II (1999). "Free-Agency and the Competitiveness of Major League Baseball," The Review of Industrial Organization, 14, 205-217.

Depken, Craig A. II (2002). "Free Agency and the Concentration of Player Talent in Major League Baseball," Journal of Sports Economics, 3, 335-53.

Eckard, Woodrow E. (2001). "Free agency, Competitive Balance, and Diminishing Returns to Pennant Contention," Economic Inquiry, 39, 430-43.

Fort, Rodney (2005). "The Golden Anniversary of 'The Baseball Players Labor Market'," Journal of Sports Economics, 6, 347-358.

Gillette, Gary, and Pete Palmer (2004). The Baseball Encyclopedia, New York: Barnes \& Noble Publishing, Inc.

Gius, Mark Paul, and Timothy R. Hylan (1996). "An Interperiod Analysis of the Salary Impact of Structural Changes in Major League Baseball: Evidence from Panel Data," in J. Fizel, E. Gustafson and L. Hadley, eds. Baseball Economics: Current Research, Praeger.

Hylan, Timothy R., Marueen J. Lage, and Michael Treglia (1996). "The Coase Theorem, Free Agency, and Major League Baseball: A Panel Study of Pitcher Mobility from 1961 to 1992," Southern Economic Journal, 62, 1029-1042.

Krautmann, Anthony C. (1999). "What's Wrong with Scully-Estimates of a Player's Marginal Revenue Product?" Economic Inquiry, 37, 369-381.

Kronmal, Richard A. (1993). "Spurious Correlation and the Fallacy of the Ratio Standard Revisited," Journal of the Royal Statistical Society. Series A (Statistics in Society), 156, 379-392.

Lahman, Sean (2005). "A Brief History of Baseball: Part I: Origins of the Game," accessed December 2005 at http://baseball1.com/bb-data/e-hist-1.html.

Levin, Richard C., George J. Mitchell, Paul A. Volcker, and George F. Will (2000). The Report of the Independent Members of the Commissioner's Blue Ribbon Panel on Baseball Economics, New York: Major League Baseball. 
Marburger, Daniel (1994). "Bargaining Power and the Structures of Salaries in Major League Baseball," Managerial and Decision Economics, 15, 433-441.

Marburger, Daniel (1996). "A Comparison of Salary Determination in the Free Agent and Salary Arbitration Markets," in J. Fizel, E. Gustafson and L. Hadley, eds., Baseball Economics: Current Research, Praeger.

Maxcy, Joel G. (2002). "Rethinking Restrictions on Player Mobility in Major League Baseball," Contemporary Economic Policy, 20, 145-59.

Medoff, Marshall H. (1976). "On Monoposonistic Exploitation in Professional Baseball," Quarterly Review of Economics and Business, 16, 113-121.

Persons, Warren M. (1931). Forecasting Business Cycles, New York: Wiley and Sons.

Pigou, Arthur C. (1920). The Economics of Welfare, London: Macmillan and Co.

Rottenburg, Simon (1956). "The Baseball Players' Labor Market," The Journal of Political Economy, 64, 242-58.

Scully, Gerald W (1974). "Pay and Performance in Major League Baseball," The American Economic Review, 64, 915-30.

Scully, Gerald W. (1989) The Business of Major League Baseball, Chicago: University of Chicago Press.

Seymour, Harold (1960). Baseball: The Early Years, New York: Oxford University Press.

Sommers, Paul M. and Noel Quinton (1982). "Pay and Performance in Major League Baseball: The Case of the First Family of Free Agents," Journal of Human Resources, 17, 426-436.

Spalding, Albert G. (1991) Base Ball: America's National Game 1839-1891, Edited by Samm Coombs and Bob West. San Francisco: Halo Books.

Woodward, E. Woodrow (2001) "The Origin of the Reserve Clause: Owner Collusion Versus 'Public Interest,'" Journal of Sports Economics, 2, 113-130. 


\section{Appendix}

A player's slugging average does not have a one-to-one relationship with the team's slugging percentage; the marginal product from the team production function overstates the marginal product of an individual player's offensive or pitching contribution. To see this, note that team slugging percentage can be written as

$$
T S A_{k}=\frac{\sum_{i} H_{i k}+\sum_{i} D_{i k}+2 \sum_{i} T_{i k}+3 \sum_{i} H R_{i k}}{\sum_{i} A B_{i k}},
$$

where $i=1 \ldots N_{k}$ indexes the number of players on team $k, H$ is the number of hits (of any kind), $D$ is the number of doubles, $T$ is the number of triples, and $H R$ is the number of homeruns hit by the players on the team, and $A B$ is the number of at-bats by the players on the team.

An individual player's slugging average is:

$$
S A_{i}=\frac{H_{i}+D_{i}+2 T_{i}+3 H R_{i}}{A B_{i}}
$$

which can be rewritten as

$$
A B_{i} S A_{i}=H_{i}+D_{i}+2 T_{i}+3 H R_{i} .
$$

Summing both sides of equation (6) over the $N$ players on team $k$ one obtains:

$$
\sum_{i} A B_{i k} S A_{i k}=\sum_{i} H_{i k}+\sum_{i} D_{i k}+2 \sum_{i} T_{i k}+3 \sum_{i} H R_{i k} .
$$

The right hand side of equation (7) equals $T S A_{k} \times \sum_{i} A B_{i k}$ so that the team's slugging average can be written as

$$
\sum_{i} A B_{i k} S A_{i k}=T S A_{k} \sum_{i} A B_{i k}
$$

This, in turn, suggests that the marginal impact of a player's slugging average on team slugging percentage can be written as:

$$
\frac{d T S A_{k}}{d S A_{i}}=\frac{A B_{i}}{\sum_{i} A B_{i k}} d S A_{i}
$$

where the first term is the percentage of a team's at-bats for player $i$ and $d S P_{i}$ is the change in a player's individual slugging percentage. ${ }^{23}$

For non-pitchers, slugging average captures their contribution to team win percentage. However, during the 1880s all pitchers hit, and therefore pitchers contributed to team win percentage through their offensive and pitching efforts.

It is possible to derive the marginal impact of a pitcher's individual strikeout-to-walk ratio on the team's strikeout-to-walk ratio as:

$$
\frac{d T S W_{k}}{d S W_{i}}=\frac{K_{i}}{\sum_{i} K_{i k}} d S W_{i}
$$

An individual pitcher's contribution to the team strikeout-to-walk ratio is the product of that pitcher's strikeout-to-walk ratio and the percentage of team strikeouts for which the pitcher accounted.

\footnotetext{
${ }^{23}$ This result is alluded to, but not derived, by Chelius and Dworkin (1980) and Krautmann (1999).
} 
Combining the two derivatives it is possible to calculate each player's marginal win percentage as:

$$
M W P_{i t}=\left(1000 \times S A_{i t} \times P E R A B_{i t} \times M P_{T S A}\right)+\left(100 \times S W_{i t} \times P E R S O_{i t} \times M P_{T S W}\right),
$$

where $S P_{i t}$ denotes player $i$ 's slugging average in year $t, P E R A B_{i t}$ denotes player $i$ 's percentage of team at-bats in year $t, M P_{T S A}$ denotes the marginal product of team slugging percentage, $S W_{i t}$ denotes player $i$ 's strikeout-to-walk ratio (pitched) in year $t, P E R S O_{i t}$ denotes player $i$ 's share of team strikeouts pitched in year $t$, and $M P_{T S W}$ is the marginal product of team strikeout-to-walk ratio. 
Table 1: Descriptive Statistics of the Data

Team Data (1880-1889)

\begin{tabular}{|c|c|c|c|c|c|}
\hline Variable & Description & Mean & Std.Dev. & Min & Max \\
\hline WinPer & Team win percentage & 490.17 & 137.71 & 171.71 & 824.56 \\
\hline Attendance & Team home attendance & $105,691.30$ & $73,148.44$ & 11,000 & 353,690 \\
\hline $\mathrm{TR}$ & Real total Revenue & $980,443.20$ & $691,850.90$ & $96,470.01$ & $3,393,656$ \\
\hline TSA & Team slugging average & 336.23 & 35.99 & 253.03 & 445.71 \\
\hline TSW & Team strikeout-to-walk ratio & 209.43 & 115.98 & 56.84 & 684.54 \\
\hline CONT & Less than five games from first & 0.19 & 0.39 & 0 & 1 \\
\hline OUT & More than 25 games from first & 0.46 & 0.50 & 0 & 1 \\
\hline NL & Team played in National League & 0.51 & 0.50 & 0 & 1 \\
\hline UA & Team played in United Association & 0.05 & 0.22 & 0 & 1 \\
\hline $\mathrm{AA}$ & Team played in American Association & 0.43 & 0.49 & 0 & 1 \\
\hline Obs/Teams & $154 / 40$ & & & & \\
\hline \multicolumn{6}{|c|}{ Player Data } \\
\hline Variable & Description & Mean & Std.Dev. & Min & Max \\
\hline$S A L A R Y$ & Nominal salary & $2,461.38$ & 989.13 & 875 & 7,000 \\
\hline$R S A L A R Y$ & Real salary (2004 dollars) & $45,871.65$ & $19,116.55$ & $15,373.75$ & 131,040 \\
\hline $\ln S A L A R Y$ & Log of real salary & 10.64 & 0.47 & 9.64 & 11.78 \\
\hline$E X P L O I T$ & Pigouvian Exploitation $=M R P_{i} / w_{i}$ & 2.56 & 1.46 & 0.19 & 8.92 \\
\hline$R C$ & Binding reserve clause (1887-1889) & 0.43 & 0.49 & 0 & 1 \\
\hline$M W P$ & Marginal Win Percentage & 45.67 & 20.83 & 1.85 & 154.70 \\
\hline Experience & Player experience in years & 5.85 & 3.72 & 0 & 18 \\
\hline Experience $^{2}$ & Quadratic of experience & 48 & 59.40 & 0 & 324 \\
\hline NewTeam & Player changed teams & 0.18 & 0.38 & 0 & 1 \\
\hline NewLeague & Player changed leagues & 0.03 & 0.17 & 0 & 1 \\
\hline NonPitcher & Player is not a pitcher & 0.60 & .049 & 0 & 1 \\
\hline $\begin{array}{l}\text { MacroIndex } \\
\text { Obs/Players }\end{array}$ & $\begin{array}{l}\text { Index of Manufacturing Production } \\
200 / 29\end{array}$ & 33.31 & 3.35 & 26.8 & 38.60 \\
\hline
\end{tabular}




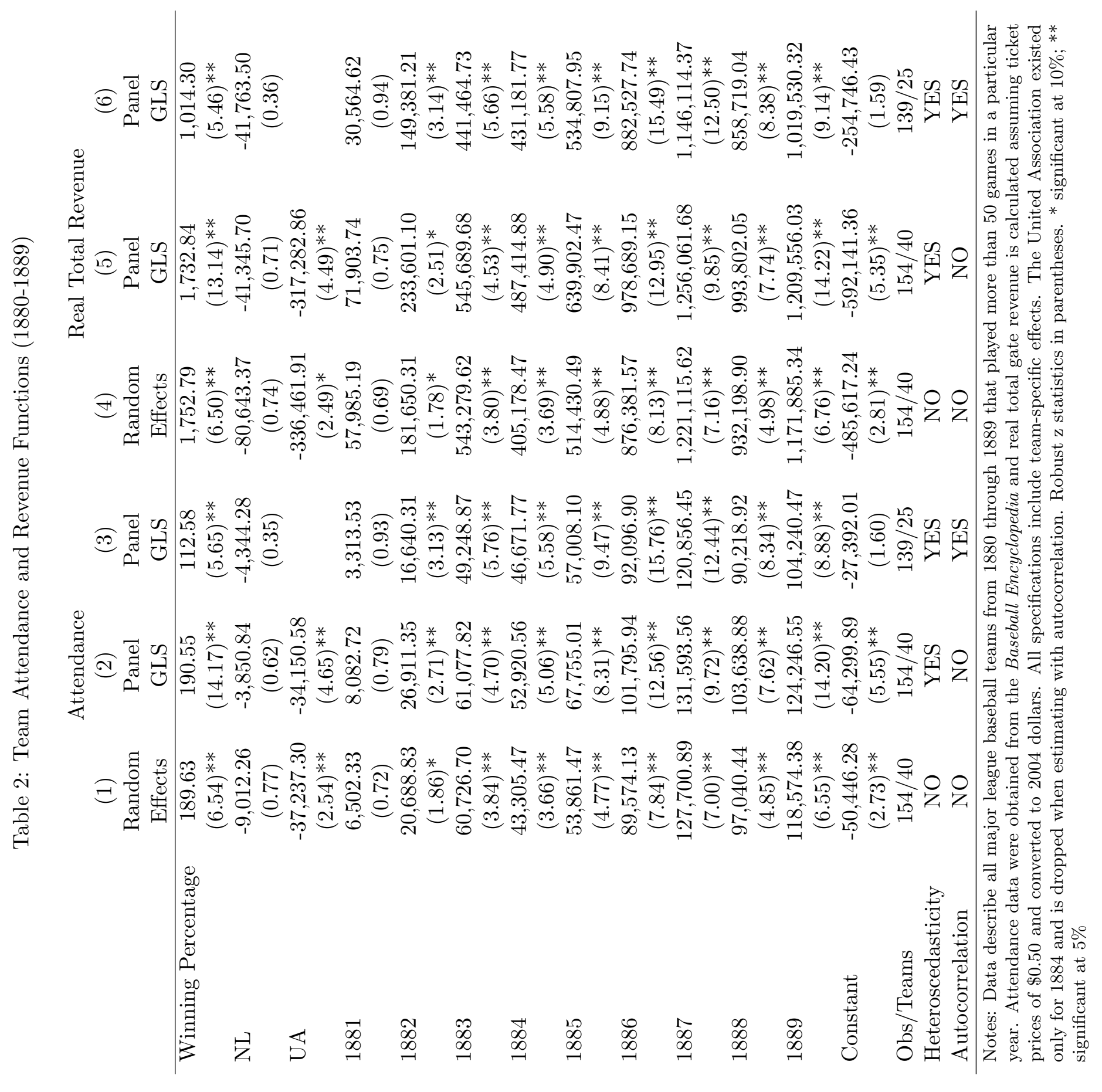




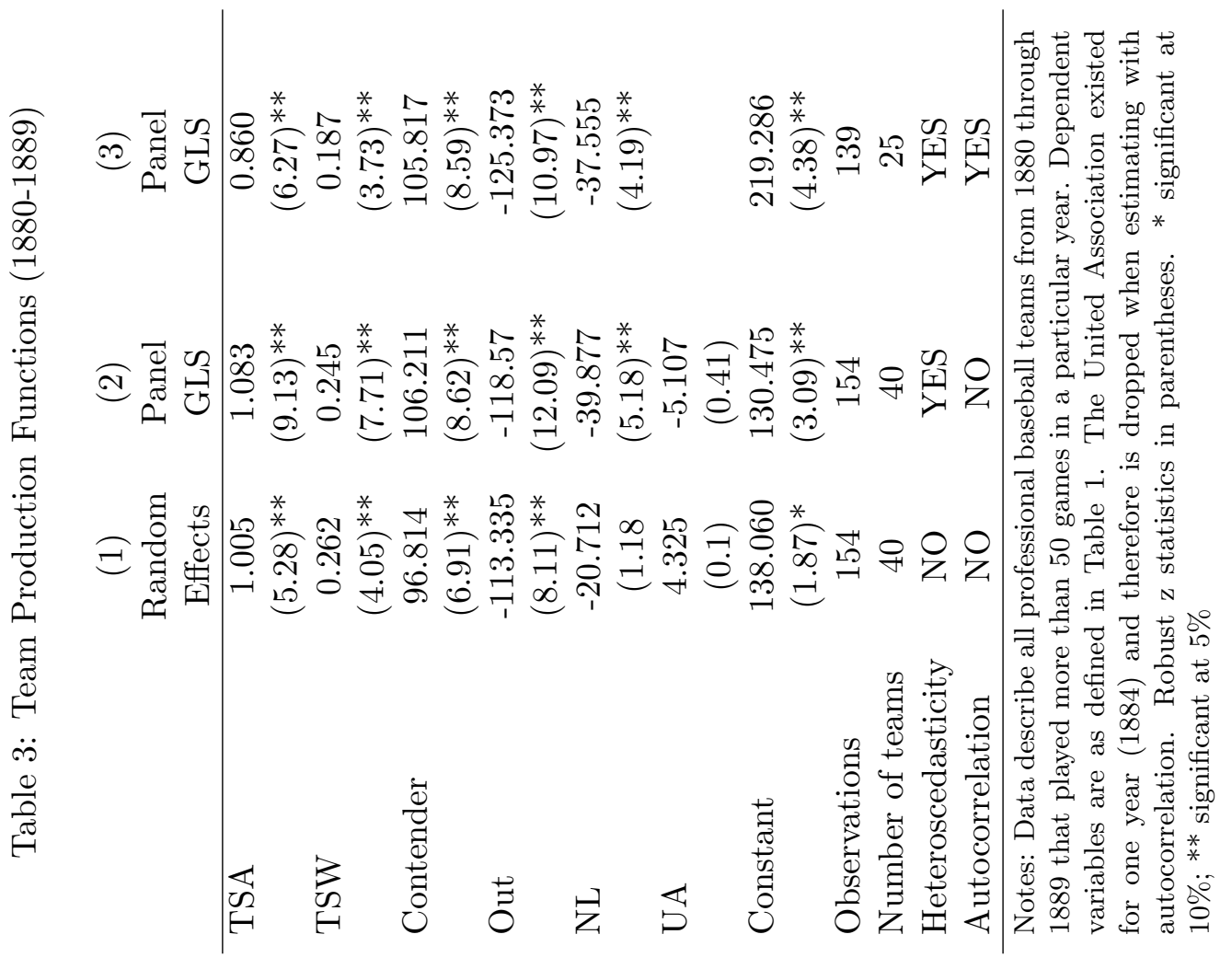




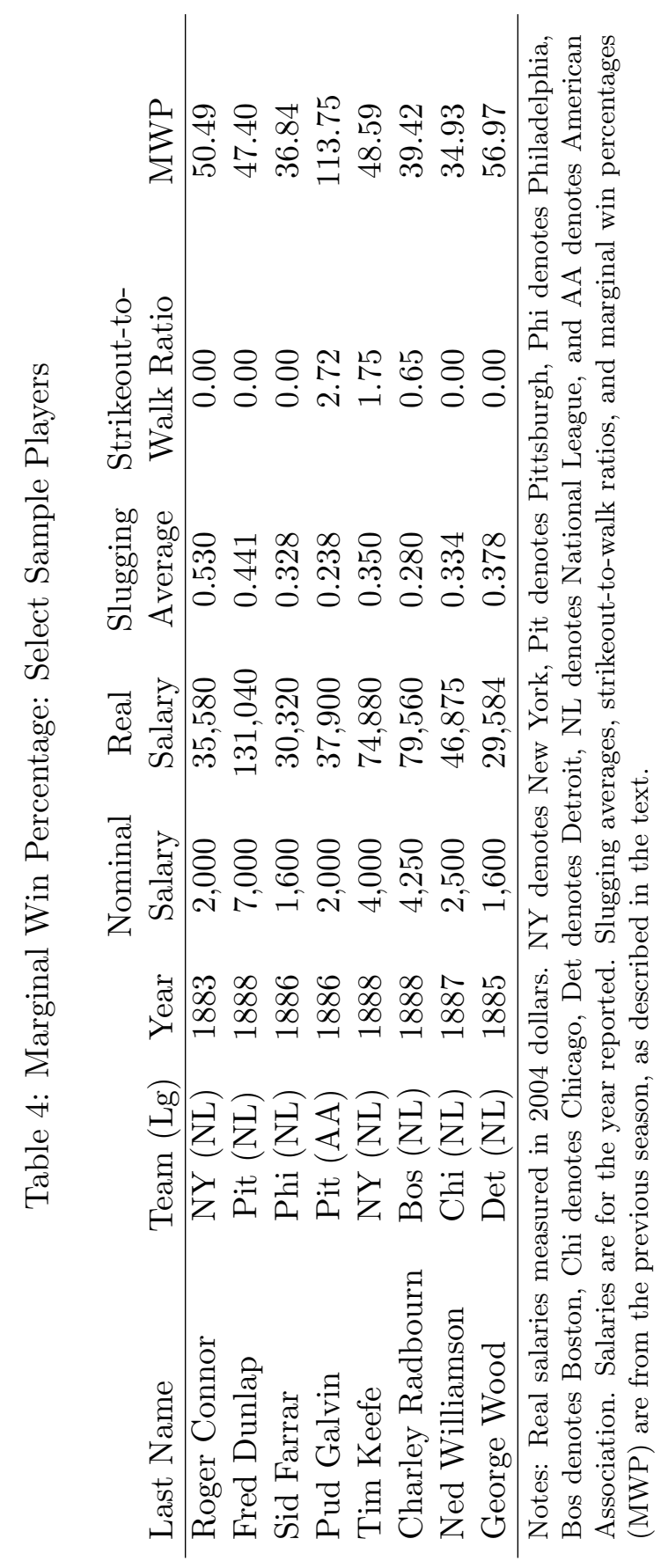




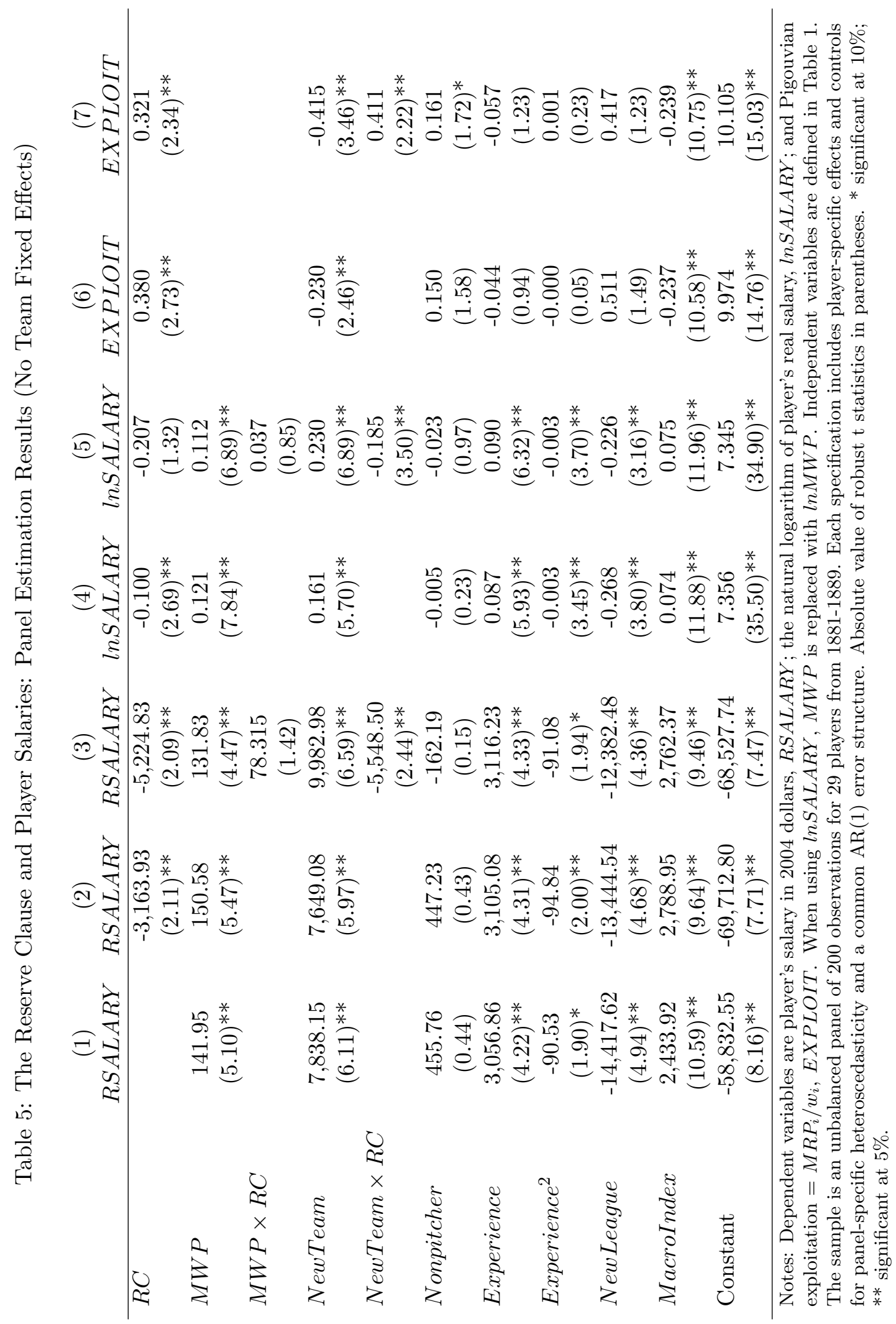




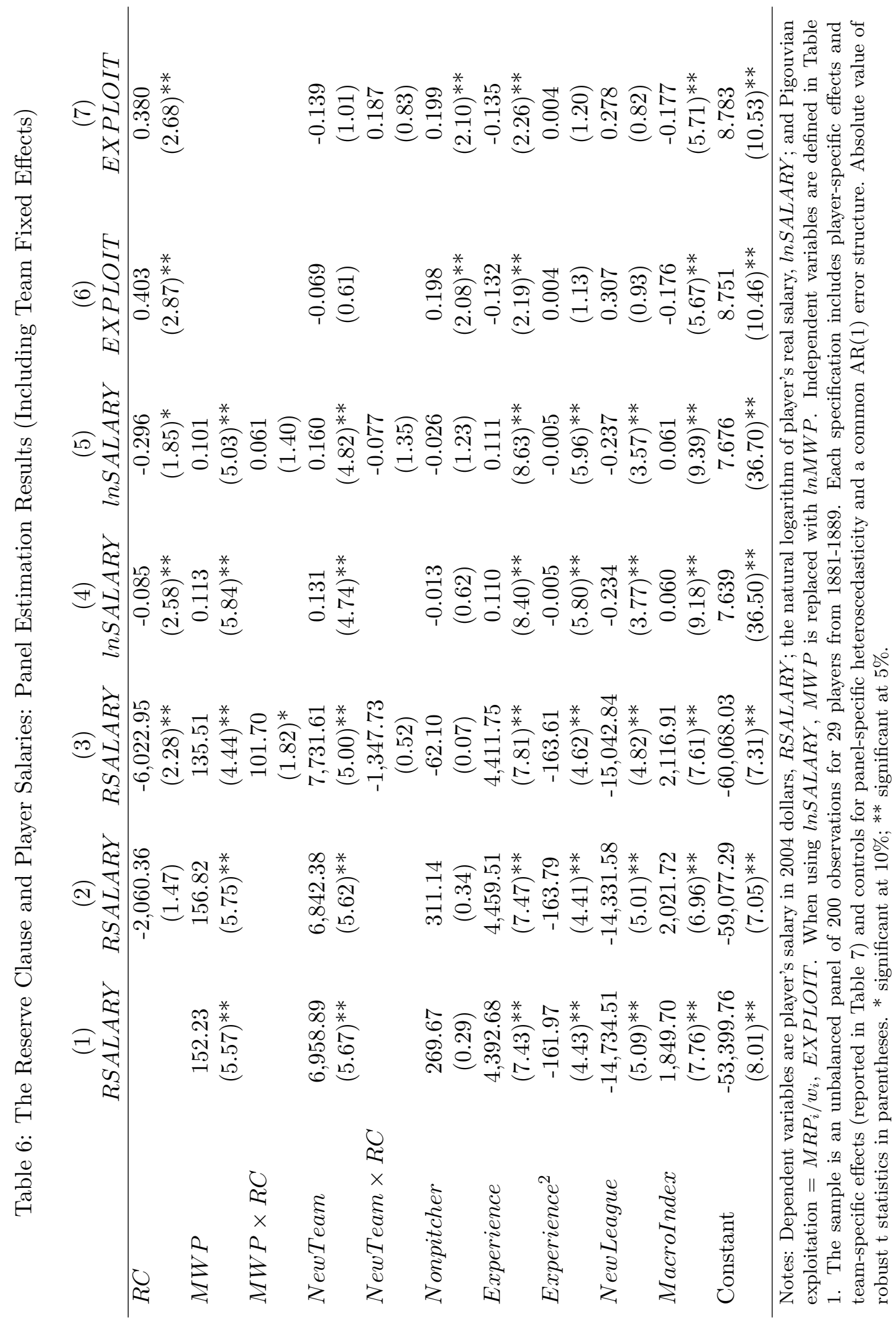




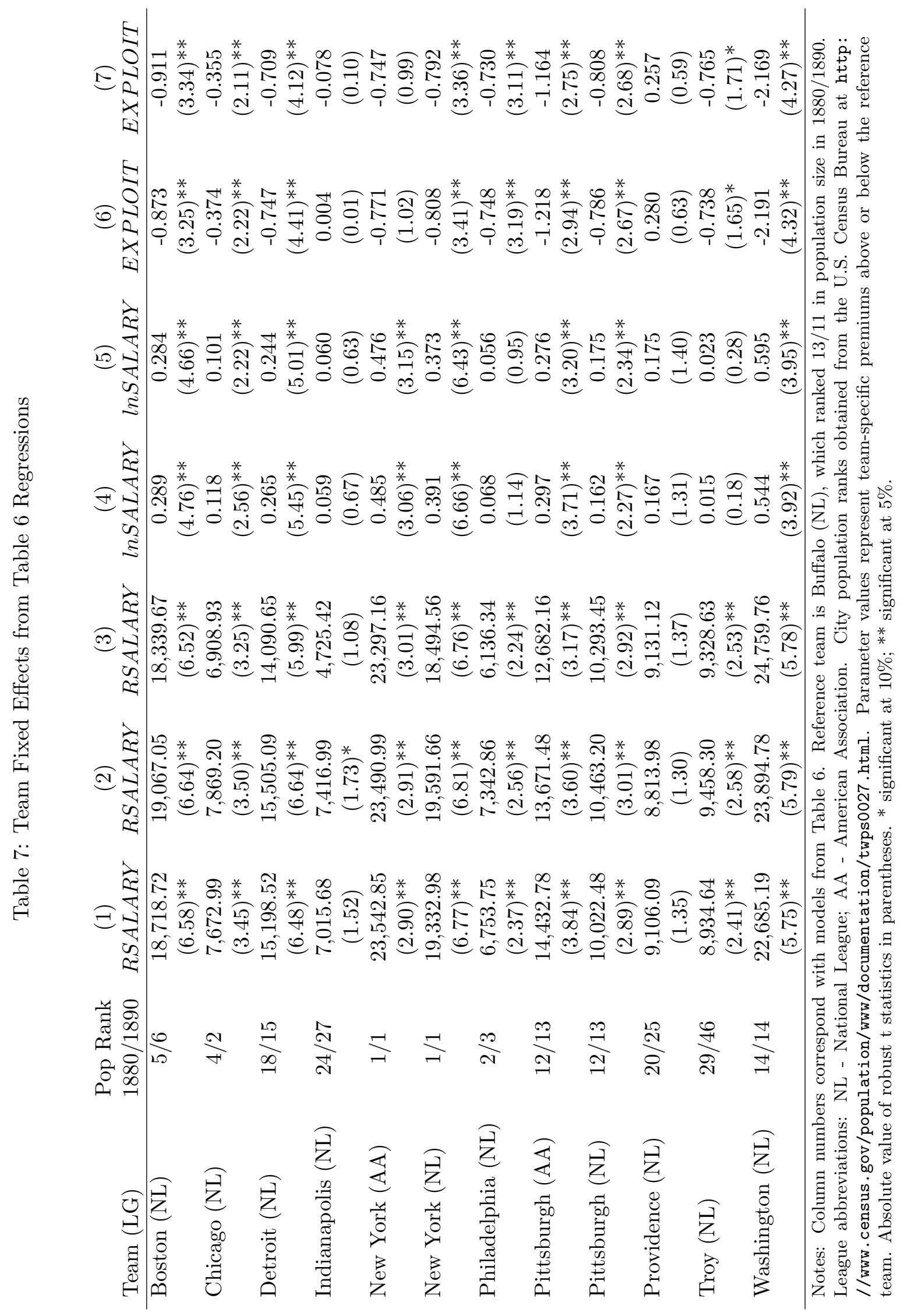


Figure 1: Estimated Team Salary Premiums vs. Host City Population Rank in 1890

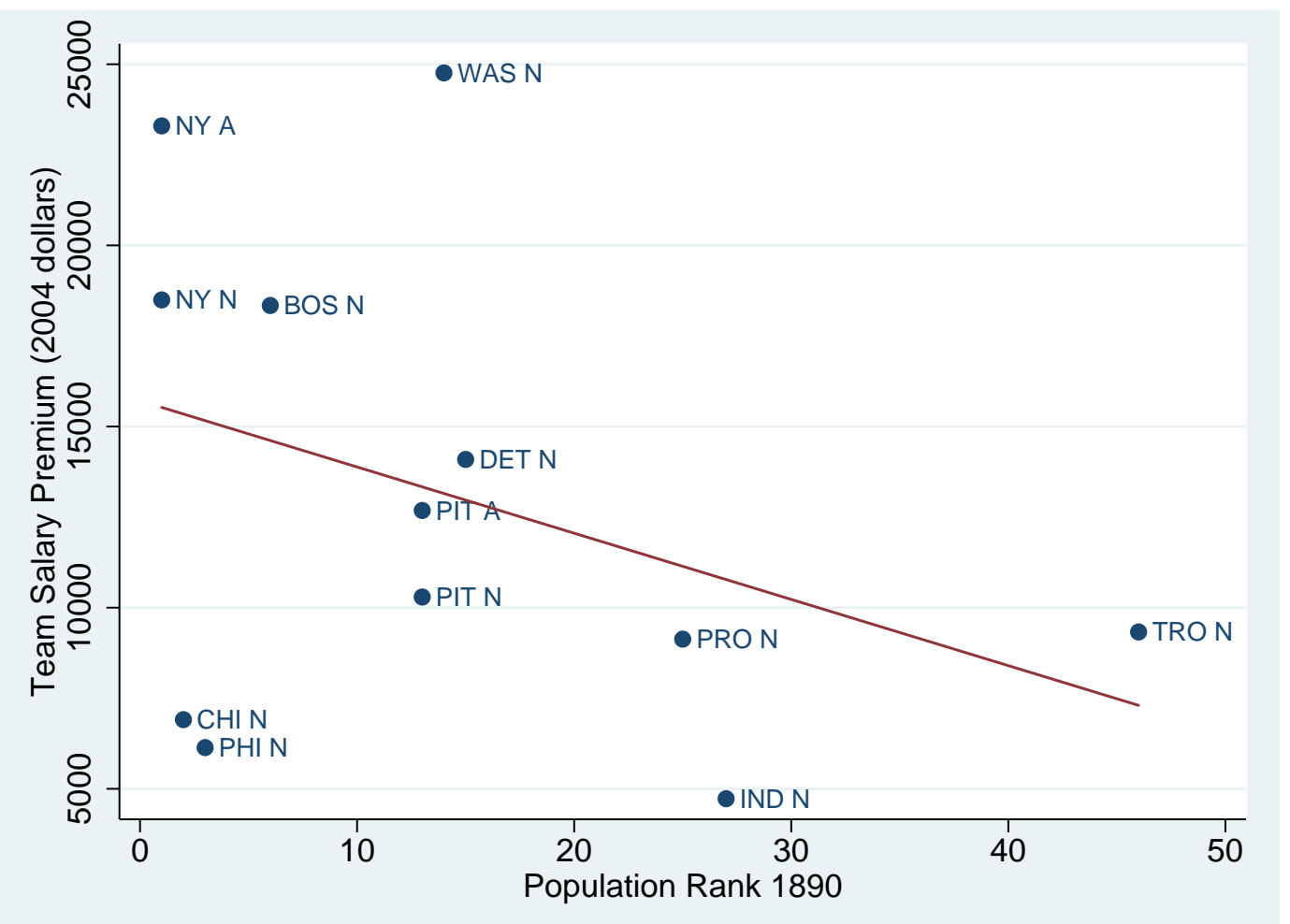

Notes: Team salary premiums are from Model (3) in Table (7). City population ranks obtained from the U.S. Census Bureau at http://www. census.gov/population/www/documentation/twps0027. html 